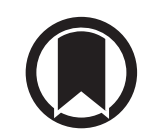

CrossMark

\title{
Global Strategy for the Diagnosis, Management, and Prevention of Chronic Obstructive Lung Disease: the GOLD science committee report 2019
}

\author{
Dave Singh ${ }^{1}$, Alvar Agusti $^{2}$, Antonio Anzueto $^{3}$, Peter J. Barnes ${ }^{4}$, \\ Jean Bourbeau ${ }^{5}$, Bartolome R. Celli (1) ${ }^{6}$, Gerard J. Criner ${ }^{7}$, Peter Frith ${ }^{8}$, \\ David M.G. Halpin ${ }^{9}$, Meilan Han ${ }^{10}$, M. Victorina López Varela ${ }^{11}$, \\ Fernando Martinez ${ }^{12}$, Maria Montes de Oca ${ }^{13}$, Alberto Papi ${ }^{14}{ }^{14}$, Ian D. Pavord ${ }^{15}$, \\ Nicolas Roche ${ }^{16}$, Donald D. $\operatorname{Sin}^{17}$, Robert Stockley ${ }^{18}$, Jørgen Vestbo ${ }^{1}$, \\ Jadwiga A. Wedzicha ${ }^{4}$ and Claus Vogelmeier ${ }^{19}$
}

@ERSpublications

The GOLD 2019 report has new pharmacological treatment recommendations, based on recent evidence from clinical trials. Blood eosinophils are recommended as a biomarker to support clinical decisions regarding the use of inhaled corticosteroids. http://ow.ly/oerU30nSKUX

Cite this article as: Singh D, Agusti A, Anzueto A, et al. Global Strategy for the Diagnosis, Management, and Prevention of Chronic Obstructive Lung Disease: the GOLD science committee report 2019. Eur Respir J 2019; 53: 1900164 [https://doi.org/10.1183/13993003.00164-2019].

ABSTRACT Precision medicine is a patient-specific approach that integrates all relevant clinical, genetic and biological information in order to optimise the therapeutic benefit relative to the possibility of sideeffects for each individual. Recent clinical trials have shown that higher blood eosinophil counts are associated with a greater efficacy of inhaled corticosteroids (ICSs) in chronic obstructive pulmonary disease (COPD) patients. Blood eosinophil counts are a biomarker with potential to be used in clinical practice, to help target ICS treatment with more precision in COPD patients with a history of exacerbations despite appropriate bronchodilator treatment.

The Global Initiative for Chronic Obstructive Lung Disease (GOLD) 2017 pharmacological treatment algorithms, based on the $\mathrm{ABCD}$ assessment, can be applied relatively easily to treatment-naive individuals at initial presentation. However, their use is more problematic during follow-up in patients who are already on maintenance treatment. There is a need for a different system to guide COPD pharmacological management during follow-up.

Recent large randomised controlled trials have provided important new information concerning the therapeutic effects of ICSs and long-acting bronchodilators on exacerbations. The new evidence regarding blood eosinophils and inhaled treatments, and the need to distinguish between initial and follow-up pharmacological management, led to changes in the GOLD pharmacological treatment recommendations. This article explains the evidence and rationale for the GOLD 2019 pharmacological treatment recommendations. 


\section{Introduction}

Chronic obstructive pulmonary disease (COPD) is a complex condition, with many different components and mechanisms contributing to its pathophysiology and clinical presentation [1]. Precision medicine is a patient-specific approach that integrates all relevant clinical, genetic and biological information for each individual in order to optimise pharmacological treatment, enabling the therapeutic benefit to be maximised for an individual relative to the possibility of side-effects $[1,2]$. For instance, while randomised controlled trials (RCTs) of inhaled corticosteroid (ICS)-containing combinations have consistently demonstrated a clinical benefit for the ICS component on a group basis, the presence and magnitude of effect varies greatly between individuals [3]. Furthermore, there are concerns about the long-term side-effects of ICS use in COPD, in particular pneumonia but also osteoporosis, diabetes, tuberculosis and non-tuberculous mycobacteria infection $[1,3]$.

Eosinophilic airway inflammation is present in a subset of COPD patients [4, 5]. Short-term clinical trials have shown that higher sputum eosinophil counts in stable COPD patients predict a greater lung function response to corticosteroids $[6,7]$. Sputum eosinophil measurement is not widely available in most centres, limiting its use in daily clinical practice, and patients cannot always provide adequate samples for analysis. Blood eosinophil measurements are an alternative biomarker reflecting eosinophilic airway inflammation in COPD patients [4]. Recent clinical trials have shown that blood eosinophil counts are associated with the efficacy of ICSs in COPD patients [8-13], suggesting the use of this biomarker to identify individuals with a greater probability of treatment benefit with ICSs. This provides an opportunity in clinical practice to target ICS treatment with more precision in COPD patients with a history of exacerbations despite appropriate bronchodilator treatment.

The Global Initiative for Chronic Obstructive Lung Disease (GOLD) 2017 strategy document recommended that an assessment (ABCD grouping) based on symptoms and exacerbation risk should be performed after the initial diagnosis of COPD [14]. The ABCD grouping was designed to facilitate a more individualised approach to pharmacological management based on clinical characteristics, with different recommendations for initial treatment and subsequent follow-up for each group [14]. While these treatment algorithms can be applied relatively easily to treatment-naive individuals at initial presentation, their use is more problematic during follow-up in patients who are already on maintenance treatment. One key issue is that the grouping applied to an individual may change over time, which could reflect either a positive response to treatment or worsening of disease [15]. A potential solution is to use $\mathrm{ABCD}$ only for initial treatment, and use a different system to guide pharmacological management in COPD patients who are in follow-up and already receiving treatment.

Recent large RCTs focusing on exacerbation prevention have provided important new information concerning the therapeutic effects of ICSs and long-acting bronchodilators $[9,10,16]$. This article explains the GOLD Science Committee's interpretation of the evidence for blood eosinophils as a biomarker in COPD patients and recent RCT evidence concerning exacerbation prevention. We explain how this information was incorporated into the GOLD 2019 recommendations, which set out to provide more clarity regarding initial and follow-up pharmacological management [17].

Initial and follow-up pharmacological management; more clarity needed in GOLD GOLD 2017 pharmacological treatment recommendations were based on the ABCD categorisation of patients at diagnosis [14]. Using this system to decide on an initial treatment plan is relatively straightforward. Following the relevant algorithm to decide on the next steps after initial treatment requires knowledge of the

Affiliations: ${ }^{1}$ University of Manchester, Manchester, UK. ${ }^{2}$ Hospital Clínic, Universitat de Barcelona, CIBERES, Barcelona, Spain. ${ }^{3}$ University of Texas Health Science Center, San Antonio, TX, USA. ${ }^{4}$ National Heart and Lung Institute, London, UK. ${ }^{5}$ McGill University Health Centre, Montreal, QC, Canada. ${ }^{6}$ Brigham and Women's Hospital Boston, Boston, MA, USA. ${ }^{7}$ Lewis Katz School of Medicine at Temple University, Philadelphia, PA, USA. ${ }^{8}$ Flinders University College of Medicine and Public Health, Adelaide, Australia. ${ }^{9}$ Royal Devon and Exeter Hospital, Exeter, UK. ${ }^{10}$ University of Michigan School of Medicine, Ann Arbor, MI, USA. ${ }^{11}$ Universidad de la República Montevideo, Montevideo, Uruguay. ${ }^{12}$ New York-Presbyterian Hospital, Weill Cornell Medical Center, New York, NY, USA. ${ }^{13}$ Universidad Central de Venezuela, Caracas, Venezuela. ${ }^{14}$ Cardiorespiratory and Internal Medicine Unit, Dept of Medical Sciences, University of Ferrara, Ferrara, Italy. ${ }^{15}$ Respiratory Medicine Unit, Oxford Respiratory NIHR BRC, Nuffield Dept of Medicine, Oxford, UK. ${ }^{16}$ Hôpital Cochin (AP-HP), University Paris Descartes, Paris, France. ${ }^{17}$ University of British Columbia, Vancouver, BC, Canada. ${ }^{18}$ University Hospital, Birmingham, UK. ${ }^{19}$ Dept of Medicine, Pulmonary and Critical Care Medicine, University Medical Center Giessen and Marburg, Philipps University Marburg, Member of the German Center for Lung Research (DZL), Marburg, Germany.

Correspondence: Dave Singh, University of Manchester, Medicines Evaluation Unit, The Langley Building, Manchester University NHS Foundation Hospital Trust, Southmoor Road, Manchester, M23 9QZ, UK. E-mail: dsinghameu.org.uk 
clinical response to the previous treatment, which guides whether to escalate, switch, de-escalate or maintain the current regimen [15]. These important details regarding the response to previous treatment may be lost when the GOLD 2017 treatment algorithms are applied for the first time to a COPD patient who is already on maintenance inhaled treatment. Furthermore, a beneficial response to the previous treatment may lead to changes in the GOLD ABCD grouping and the clinician may be confused about whether this change should lead to the subsequent withdrawal of a beneficial pharmacological treatment. COPD patients can change their GOLD group over time [18] and in such situations it is unclear how the ABCD system should be used.

GOLD 2019 retains the ABCD grouping to decide on appropriate initial pharmacological treatment (figure 1) [17]. However, GOLD 2019 states that the ABCD grouping should not be used for patients who are already on maintenance treatment. To make clearer recommendations for such patients, distinct treatment pathways have been constructed for pharmacological management during follow-up (figure 2). Symptoms (dyspnoea and exercise limitation) and exacerbations are still the focus of treatment, and there are separate algorithms for each of these treatable traits [19]. The clinician needs to decide the predominant trait that requires further effective treatment at that point in time and use the relevant algorithm; the exacerbation algorithm should be used for patients suffering with both symptoms and exacerbations. The patient should be placed within the relevant algorithm according to their current treatment and recommendations for treatment escalation, switching or de-escalation utilised.

Both follow-up treatment algorithms include all the currently available inhaled monotherapy and combination treatment classes, in order to encompass all previous treatment possibilities. This explains why ICS/long-acting $\beta_{2}$-agonist (LABA) is included in the dyspnoea algorithm; it is not recommended as a treatment for dyspnoea (as no escalation arrow leads towards this treatment), but is included for those patients who are currently being treated with ICS/LABA and now have dyspnoea that needs further treatment. Similarly, LABAs or long-acting muscarinic antagonists (LAMAs) are stated at the top of each algorithm to cover both of these previous treatment possibilities. The most appropriate treatment algorithm to use should be re-evaluated at each clinic visit, as these pathways have been constructed so that the patient can be switched from one to the other as appropriate.

The dyspnoea algorithm recommends escalation using additional long-acting bronchodilator treatment for breathlessness and closely follows the recommendations of the GOLD 2017 report, albeit in a different format. For patients with dyspnoea who are already treated with a dual bronchodilator or triple combination, the option to switch molecules or inhaler device has been added, and there is a reminder to investigate other possible causes of dyspnoea such as heart failure and pulmonary hypertension. Non-pharmacological management approaches including pulmonary rehabilitation should also be considered. The exacerbation pathway recommendations differ from the GOLD 2017 report in both scientific content and format, due to the incorporation of blood eosinophils as a biomarker and recent evidence from RCTs.

\section{The evidence for blood eosinophils as a biomarker in COPD}

Relationship of blood to lung eosinophils

Bronchoscopic and sputum sampling shows the presence of increased eosinophil numbers in some COPD patients $[4,20]$, promoting the concept of a subgroup of patients with "eosinophilic COPD" due to the

\section{INITIAL PHARMACOLOGICAL TREATMENT}

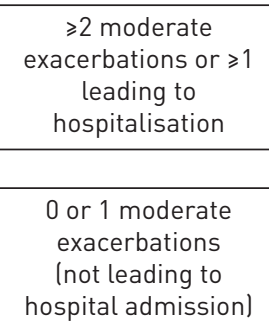

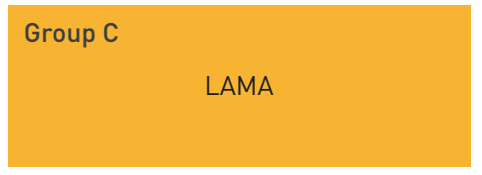

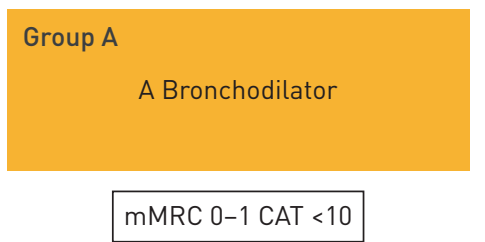

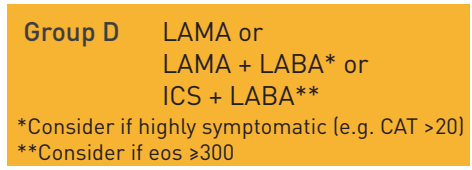

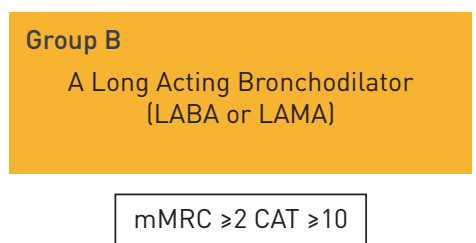

FIGURE 1 Global Initiative for Chronic Obstructive Lung Disease 2019 recommendations for initial pharmacological management in chronic obstructive pulmonary disease (COPD). LAMA: long-acting muscarinic antagonist; LABA: long-acting $\beta_{2}$-agonist; ICS: inhaled corticosteroid; CAT: COPD Assessment Test; eos: blood eosinophil count (cells. $\mu \mathrm{L}^{-1}$ ); mMRC: modified Medical Research Council dyspnoea questionnaire. Reproduced with permission from [17]. 


\section{FOLLOW-UP PHARMACOLOGICAL TREATMENT}

1. IF RESPONSE TO INITIAL TREATMENT IS APPROPRIATE, MAINTAIN IT.

2. IF NOT: $\checkmark$ Consider the predominant treatable trait to target (dyspnoea or exacerbations)

- Use exacerbation pathway if both exacerbations and dyspnoea need to be targeted

$\checkmark$ Place patient in box corresponding to current treatment and follow indications

$\checkmark$ Assess response, adjust and review

$\checkmark$ These recommendations do not depend on the ABCD assessment at diagnosis

- DYSPNOEA •

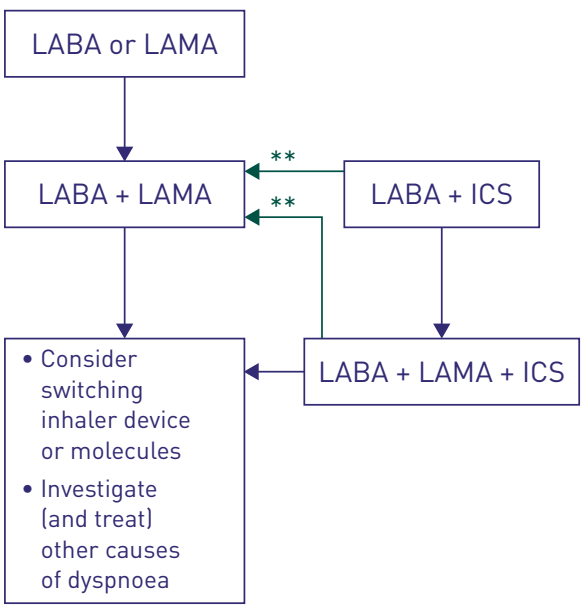

- EXACERBATIONS •

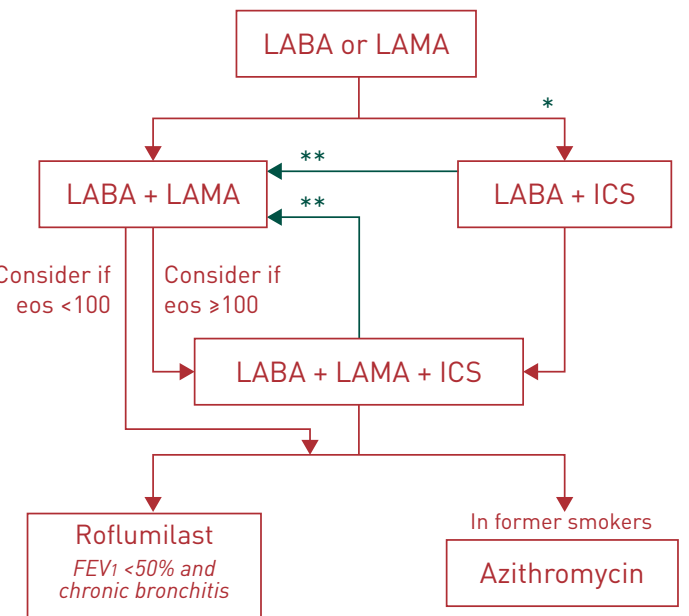

eos = blood eosinophil count (cells $\left.\mu L^{-1}\right)$

${ }^{*}$ Consider if eos $\geqslant 300$ or eos $\geqslant 100$ AND $\geqslant 2$ moderate exacerbations/1 hospitalisation

${ }^{* *}$ Consider de-escalation of ICS or switch if pneumonia, inappropriate original indication or lack of response to ICS

FIGURE 2 Global Initiative for Chronic Obstructive Lung Disease 2019 recommendations for follow-up pharmacological management. LABA: long-acting $\beta_{2}$-agonist; LAMA: long-acting muscarinic antagonist; ICS: inhaled corticosteroid; FEV1: forced expiratory volume in $1 \mathrm{~s}$. Reproduced with permission from [17].

increased number of these cells in the airways. There is a statistical correlation between blood and sputum eosinophil numbers in COPD patients, although the relationship remains moderate to weak [5, 21, 22]. However, sputum eosinophil counts are prone to considerable intersample variability $[23,24]$ and should not be regarded as the "gold standard" biomarker of eosinophilic lung inflammation. Higher blood eosinophil counts are associated with greater eosinophil counts in lung tissue samples [4, 25] and pathological differences including increased reticular basement membrane thickening (subepithelial fibrosis) [4].

\section{Variability of blood eosinophils}

Factors that can influence blood eosinophil counts include sepsis and oral corticosteroids, which reduce counts [5]. The intraclass correlation coefficient (ICC) of repeat blood eosinophil counts is reported as 0.64 at 1 year $(n=17724)$, increasing to 0.70 when excluding patients where oral corticosteroid use and/or concurrent exacerbations may have influenced counts [26], 0.87 at $>2$ years $(n=59)$ [27] and 0.57 at 3 years $(n=1483)$ [28]. ICC values can be interpreted as excellent $(>0.75)$, fair to good $(0.40-0.75)$ or poor $(<0.40)$ [26]. These ICC values for repeated blood eosinophil counts in COPD patients, therefore, lie in the fair to good or excellent categories and are similar to reported values for cholesterol (ICC 0.70-0.72) and glycated haemoglobin (HbAlc; ICC 0.59), which are commonly used biomarkers in the management of other diseases [26]. It should be noted that cholesterol and HbAlc are biomarkers used to monitor the effects of pharmacological interventions, while this article discusses the use of blood eosinophil counts in COPD to predict pharmacological effects.

Analysis of the number of patients that cross a predetermined threshold over time shows good stability at lower threshold values [5]. Using the $<150$ eosinophils $\mu \mathrm{L}^{-1}$ threshold, $87 \%$ and $86 \%$ of results remained stable at 6 months and $>2$ years, respectively [27]. Greater variability has been observed with higher threshold values, e.g. using 340 cells. $\mu \mathrm{L}^{-1}$, stability was $85 \%$ at 6 months and $62 \%$ at 2 years [29]. The 
variability observed with multiple testing (at least three measurements) [26] remains greater at higher eosinophil counts; $88 \%$ with a first blood eosinophil count $\geqslant 150$ cells $\mu \mathrm{L}^{-1}$ had a subsequent mean value $\geqslant 150$ cells $\mu \mathrm{L}^{-1}$, while for a first count $\geqslant 300$ cells $\mu \mathrm{L}^{-1}$ the proportion with a subsequent mean above this level was $68 \%$ [26]. For the $>300$ eosinophils $\mu \mathrm{L}^{-1}$ threshold, observational cohorts report that $15.8 \%, 19 \%$ and $20 \%$ of values are always above this level after 1 or 2 years of follow-up, with the proportion at a single measurement being higher [27, 30, 31]. The percentage of COPD patients identified above or below given blood eosinophil thresholds may be influenced by geographical variations.

\section{Blood eosinophils and ICS response}

Post hoc and pre-specified analyses of RCTs have evaluated the relationship between blood eosinophil counts measured before randomisation and ICS effects. The evidence from these studies is reviewed according to treatment comparison. Unless stated otherwise, the inclusion criteria of all these studies required patients to have one or more moderate or severe exacerbations in the previous year and the studies were of at least 1 year duration.

\section{ICS/LABA versus $\angle A B A$}

Three post hoc analyses of RCTs that compared ICS/LABA versus LABA all showed a similar pattern of results $[11,12,32]$; there was a continuous relationship between blood eosinophil counts and the effect of ICS on exacerbation prevention, with higher eosinophil counts predicting a greater drug response. The largest analysis $(n=4528)$ used data modelling to demonstrate that no benefit of ICS was observed at $<100$ eosinophils $\mu \mathrm{L}^{-1}$, with the effect at higher counts being larger (and more likely clinically relevant) [32]; the treatment effect at $>300$ cells $\mu \mathrm{L}^{-1}$ in this and other analyses was $\sim 50 \%$ exacerbation rate reduction $[11,12]$. The data modelling analyses also showed greater ICS effects at higher blood eosinophil counts for forced expiratory volume in $1 \mathrm{~s}$ (FEV1) and quality of life.

Post hoc analyses of other studies comparing ICS/LABA versus LABA that have used a single blood eosinophil threshold have been less informative [33]. Trying to dichotomise a COPD population using a single eosinophil threshold to define "responders" and "non-responders" is overly simplistic in this situation, as different eosinophil thresholds appear to reflect different magnitudes of ICS response: $<100$ cells $\mu \mathrm{L}^{-1}$ is associated with little or no effect, while relatively large effects are observed at $>300$ cells $\mu \mathrm{L}^{-1}$ (figure 3). This is similar to a classical pharmacological dose-response curve with drug concentration on the $\mathrm{x}$-axis and drug response on the $\mathrm{y}$-axis, except here the $\mathrm{x}$-axis is the blood eosinophil count.

\section{Triple-therapy studies (LABA/LAMA/ICS fixed combination)}

In the TRIBUTE study, a pre-specified analysis showed a greater effect of triple therapy (beclomethasone dipropionate/formoterol/glycopyrrolate) versus LAMA/LABA (glycopyrrolate/indacaterol) on exacerbation rate reduction in patients with blood eosinophils $\geqslant 2 \%(20 \%$ treatment difference; $\mathrm{p}=0.029)$ compared with $<2 \%(6 \% ; \mathrm{p}=0.68)$ [10]. Numerically similar results were obtained using $\geqslant 200 \mathrm{cells} \cdot \mu \mathrm{L}^{-1}$, although statistically significant benefit was not reached above this threshold $(\mathrm{p}=0.057)$.

The IMPACT study enrolled patients with FEV $1<50 \%$ predicted and one or more moderate or severe exacerbations in the previous year, or FEV $150-80 \%$ predicted and two or more moderate exacerbations or one severe exacerbation in the previous year [9]. These inclusion criteria enrolled a population with a relatively high exacerbation risk; $54 \%$ had two or more moderate or severe exacerbations and $26 \%$ had one

FIGURE 3 The relationship between blood eosinophil count and the effect of inhaled corticosteroid (ICS) on exacerbation prevention in chronic obstructive pulmonary disease patients.

Low likelihood of benefit

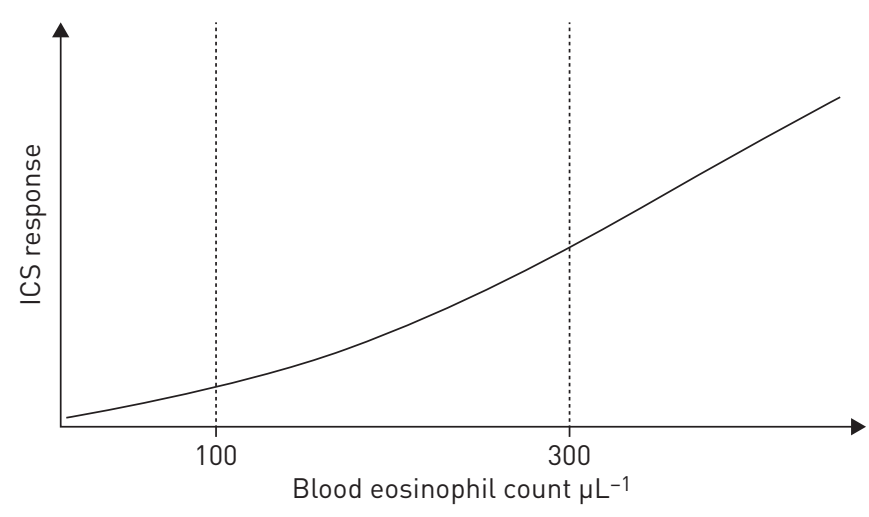


or more severe exacerbations in the previous year. There was a $25 \%$ treatment difference in the annual exacerbation rate in favour of triple therapy (fluticasone furoate/vilanterol/umeclidinium) over LAMA/ LABA (umeclidinium/vilanterol). A pre-specified analysis showed a $32 \%$ treatment difference $(\mathrm{p}<0.001)$ at $\geqslant 150$ eosinophils $\mu \mathrm{L}^{-1}$, while below this threshold the treatment difference was smaller, but still significantly in favour of triple therapy $(12 \% ; \mathrm{p}=0.034)$.

\section{ICS/LABA versus LABA/LAMA}

The FLAME study showed that LAMA/LABA (glycopyrrolate/indacaterol) had a $17 \%$ greater effect on exacerbation rate reduction than ICS/LABA (fluticasone propionate/salmeterol) [34]. Pre-specified analysis using a $2 \%$ eosinophil threshold showed no difference in treatment effect above or below this threshold [34]. Subsequent post hoc analysis using three subgroups $\left(<150,150-<300\right.$ and $\geqslant 300$ cells $\left.\mu \mathrm{L}^{-1}\right)$ revealed a different pattern of results [35]; LABA/LAMA had a much greater effect than ICS/LABA at $<150$ cells $\mu \mathrm{L}^{-1}$ ( $28 \%$ difference; $\mathrm{p}<0.001$ ), but at $150-<300$ and $\geqslant 300$ cells $\mu \mathrm{L}^{-1}$ this treatment comparison yielded smaller differences $\left(11 \%\right.$ and $7 \%$, respectively). Patients with higher eosinophil counts $\left(>600\right.$ cells $\left.\mu \mathrm{L}^{-1}\right)$ were excluded, possibly blunting the result in the $>300$ cells $\mu \mathrm{L}^{-1}$ category. This analysis supports the concept of a continuous relationship between blood eosinophils and ICS effects, with reduced ICS effects at lower blood eosinophil counts. In this study, the previous exacerbation history did not influence the treatment differences $[35,36]$, although the proportion of patients with a history of at least two exacerbations in the previous year was limited $(\sim 20 \%)$.

The IMPACT study also compared ICS/LABA (fluticasone furoate/vilanterol) with LAMA/LABA; ICS/ LABA had a $10 \%$ greater effect on exacerbation prevention in the overall population. The treatment difference was dependent on blood eosinophil counts, with LAMA/LABA having a greater effect at $<150$ cells $\mu \mathrm{L}^{-1}$, while ICS/LABA had a greater effect above this threshold. These results differ significantly from FLAME, where ICS/LABA was not superior to LAMA/LABA in any eosinophil threshold or subgroup analysis [35]. A key difference between these studies was the exacerbation risk of the enrolled populations, as most of the FLAME population had one exacerbation in the previous year [34], in contrast to the much higher risk of the IMPACT population, indicating that the effects of ICS-containing combinations are greater in higher-risk populations. Patients with a history of asthma were excluded from FLAME but were allowed to participate in IMPACT, potentially influencing the observed ICS treatment effects. The run-in treatment in the FLAME study was tiotropium, while in the IMPACT study patients continued with their own inhaled treatment. This also may have contributed to the differing results, as some patients requiring ICS would have dropped out during the FLAME run-in period.

\section{ICS step-down studies}

The WISDOM study evaluated the stepped withdrawal of ICS from triple therapy. Two post hoc analyses of WISDOM have shown a significant deleterious effect of ICS withdrawal at higher blood eosinophil counts $\left(\geqslant 300\right.$ cells $\left.\mu \mathrm{L}^{-1}\right)[8,37]$. One of these analyses showed a greater deleterious effect in patients with a prior history of two or more exacerbations, supporting the concept of greater ICS effects in higher exacerbation risk individuals. The SUNSET study enrolled patients with zero or one exacerbation $(66 \%$ and $34 \%$, respectively) in the previous year who were already on triple therapy for at least 6 months [38]. ICS withdrawal appeared to be well tolerated at $<300$ eosinophils $\mu \mathrm{L}^{-1}$, while a clinical deterioration (greater lung function loss) and more exacerbations were observed in those with $\geqslant 300$ eosinophils. $\mu \mathrm{L}^{-1}$.

\section{Other clinical trials}

Post hoc analysis of the INSPIRE study did not shown any significant differences between ICS/LABA versus LAMA using thresholds of $2 \%$ and 200 cells. $\mu \mathrm{L}^{-1}$, but other thresholds were not investigated [33]. A combined analysis of 10 studies showed that pneumonia risk was higher in patients with eosinophils $<2 \%$ independent of ICS use, although the effect size was small (3.7\% versus 3.2\%; hazard ratio $1.31,95 \%$ CI 1.06-1.62) [39]. A clinical trial reported that blood eosinophil counts may predict which patients receive benefit from oral corticosteroid treatment during exacerbations [40]. These data may help direct acute exacerbation management, but do not provide support for the use of blood eosinophils to help direct the use of ICS-containing combination inhalers.

\section{Summary: blood eosinophils and ICS response}

The clinical evidence reviewed contains subgroup analyses with reduced sample sizes. In such cases, a focus on $\mathrm{p}$-values for statistical significance may be less appropriate. However, the magnitude of effect sizes and consistency of data between studies become important considerations. A consistent pattern of results from RCTs conducted in COPD patients at increased risk of exacerbations has emerged, showing that lower eosinophil counts predict a lower or no benefit of ICS in terms of exacerbation prevention, which is particularly evident below approximately 100 eosinophils $\mu \mathrm{L}^{-1}$. The greatest ICS effects were 
consistently observed at $\geqslant 300$ eosinophils $\mu \mathrm{L}^{-1}$. These thresholds of $<100$ and $\geqslant 300$ eosinophils $\mu \mathrm{L}^{-1} \mathrm{can}$ therefore be used to help predict the likelihood and magnitude of ICS treatment benefit in clinical practice. These thresholds provide a measure of probability that can be used with other clinical information, notably exacerbation risk, to estimate the likelihood of a benefit from ICS treatment.

The different results observed when comparing the double combination treatments in the FLAME and IMPACT studies highlight that ICSs have a greater demonstrable benefit in higher exacerbation risk populations. This can influence the interpretation of blood eosinophil counts and thresholds. In patients with one moderate exacerbation in the previous year, the FLAME results indicate that LAMA/LABA is generally a preferred treatment, although ICS/LABA may be a more effective treatment for some patients with eosinophils $\geqslant 300$ cells $\mu \mathrm{L}^{-1}$. In higher-risk patients (two or more moderate exacerbations or one severe exacerbation), the IMPACT study demonstrated that the benefits of ICS/LABA over LABA/LAMA were present even at lower blood eosinophil counts, indicating that ICS/LABA use could be considered in high-risk patients at $>100$ eosinophils $\mu \mathrm{L}^{-1}$, while being preferred at higher eosinophil counts.

The number needed to treat (NNT) to prevent one exacerbation (event-based NNT) is dependent on the underlying exacerbation rate and has been approximately derived from the IMPACT results; the NNT to prevent one exacerbation with triple therapy compared with LAMA/LABA (where a 25\% reduction in exacerbation rate was observed) has been estimated to lie between 3 and 4 [3]. These event-based NNTs will vary with blood eosinophil counts, being lower at the higher eosinophil counts where greater ICS effects were observed. The event-based NNT is dependent on the comparator rate of exacerbations and so will change according to the exacerbation risk of a population. The TRIBUTE study population had a lower exacerbation risk as reflected in the previous 1-year history compared with the IMPACT population and consequently a lower rate of exacerbations was observed during the study, with a $15 \%$ difference between triple therapy and LAMA/LABA for exacerbation rate reduction. The event-based NNT calculation for this study estimates the value to lie between 11 and 12 [3], with a lower number expected at higher eosinophil counts. The person-based NNT (i.e. to make a patient exacerbation free) for IMPACT and TRIBUTE has been estimated to be 25 and 50, respectively, for triple therapy versus LAMA/LABA. These NNT estimates emphasise that exacerbation risk influences the magnitude of ICS effects on exacerbation prevention.

Blood eosinophils are a peripheral biomarker of airway eosinophil numbers and eosinophil-associated airway inflammation such as type 2 cytokines and reticular basement membrane thickening [4]. The clinical benefits of ICSs reported in COPD RCTs do not arise from suppression of blood eosinophil numbers, but are presumably due to pharmacological effects on a component/components of airway inflammation that are associated with higher blood eosinophil counts.

Overall, current evidence indicates that the individual assessment of exacerbation risk and blood eosinophil count can be combined to help predict the likelihood of clinical benefit with ICS-containing combinations. This should be coupled with an individualised assessment of the risk of side-effects, notably pneumonia, mycobacterial infection, osteoporosis, diabetes and cataracts.

\section{Relationship of blood eosinophils to clinical characteristics}

Cohort studies have investigated whether blood eosinophil counts are associated with clinical characteristics, such as exacerbation rates. The results have varied, with both negative and positive findings reported for exacerbations [30, 41, 42]. A recent publication using both cross-sectional (at baseline) and prospective data from COPDGene and ECLIPSE showed that eosinophils $\geqslant 300$ cells. $\mu \mathrm{L}^{-1}$ are associated with increased exacerbation risk [28], with the findings being most clearly demonstrated in patients at high exacerbation risk (two or more exacerbations in the previous year). This highlights that exacerbation risk, according to the history of exacerbations, influences the results of these cohort studies. Also, the study showed that an increased blood eosinophil count in COPD was not the same as stating that the patient had asthma-COPD overlap as the overlap between the two was small. Furthermore, the clinical trials already reviewed of ICS/LABA versus LABA in COPD patients with a history of exacerbations showed that ICS use reduces exacerbation rates in patients with more eosinophils, and the relationship between eosinophil counts and exacerbation rates was only seen without ICS use. Overall, the confounding factors of ICS treatment effect and clinical exacerbation risk are responsible for the heterogeneity between studies. These inconsistent data do not support the use of blood eosinophils as a biomarker to predict exacerbation risk or other clinical outcomes in the general COPD population.

\section{New evidence from clinical trials}

The TRIBUTE and IMPACT studies comparing triple therapy versus LAMA/LABA provided, for the first time, evidence of the beneficial effect of the ICS component of triple therapy on exacerbations (15\% and $25 \%$ exacerbation rate reduction, respectively) and quality of life $[9,10]$. IMPACT also reported a different 
result to FLAME [34] for the comparison of double combinations, which can be attributed mainly to the different exacerbation risk of the study populations as already discussed. These results from the TRIBUTE and IMPACT studies provide evidence to support the GOLD 2017 recommendation to escalate from LAMA/LABA to triple therapy. In contrast, the situation concerning double combinations has now been shown to be more complex, as the relative efficacy of double combinations is influenced by both exacerbation risk (and hence study enrichment regarding exacerbation history) and blood eosinophil count.

The DYNAGITO study compared the effect of LAMA/LABA (tiotropium/olodaterol) versus LAMA (tiotropium) on exacerbation prevention in patients with one or more exacerbations in the previous year $(\mathrm{n}=7880)$ [16]. A reduction of only $7 \%(\mathrm{p}=0.0498)$ in the exacerbation rate in favour of LAMA/LABA was observed, which did not meet the a priori level set for significance (0.01). The only similar previous study was SPARK, which showed that LAMA/LABA (glycopyrrolate/indacaterol) reduced moderate to severe exacerbations by $12 \%(\mathrm{p}=0.038)$ versus glycopyrrolate (the primary outcome) and $10 \%(\mathrm{p}=0.096)$ versus open-label tiotropium. Overall, DYNAGITO and SPARK demonstrate a minor additional effect of the LABA component of dual bronchodilator therapy on exacerbation prevention.

\section{Implementing new evidence into GOLD 2019 \\ Initial pharmacological management}

The large RCTs in COPD have usually been conducted in populations where the majority of individuals were already taking maintenance treatment before entering the study. Few studies have been specifically designed to evaluate pharmacological interventions in treatment-naive COPD patients. The GOLD recommendations for initial pharmacological treatment are based on existing evidence, but with the limitation that these recommendations have not been directly tested in treatment-naive populations.

The lack of new RCTs in treatment-naive COPD patients means that the GOLD 2019 initial treatment recommendations (figure 1) are mostly similar to GOLD 2017. The exception is GOLD group D, with two key changes. First, eosinophils $\geqslant 300$ cells $\mu \mathrm{L}^{-1}$ is suggested as an indicator to consider ICS/LABA treatment, as this threshold identifies patients with a higher likelihood of benefit from ICS treatment. A retrospective analysis of real-world clinical practice data supports this recommendation; the effects of ICS/ LABA as an initial treatment on exacerbation prevention were greater than LAMA treatment in patients with eosinophils $\geqslant 300$ cells $\mu \mathrm{L}^{-1}$, but not below this threshold [43]. Second, a box stating that LAMA/ LABA is a preferred treatment in GOLD 2017 has been removed due to the new evidence on exacerbation prevention showing that the magnitude of effect of LAMA/LABA over LAMA was smaller than expected (DYNAGITO) [16] and that ICS/LABA is a better treatment than LAMA/LABA in some patients (IMPACT) [9]. RCTs have demonstrated the benefits of LAMA/LABA compared with LAMA monotherapy for symptoms and quality of life $[44,45]$, so there is a practical recommendation to consider LAMA/LABA as first-line therapy in more highly symptomatic individuals.

\section{Follow-up pharmacological management}

The dyspnoea pathway (figure 2) closely follows the GOLD 2017 recommendations for groups B and D, using additional long-acting bronchodilator treatment to manage symptoms. In contrast, the follow-up exacerbation pathway is very different, as the integration of exacerbation risk and blood eosinophil counts influences the recommendations regarding the use of combination inhalers. For escalation from long-acting bronchodilator monotherapy to either ICS/LABA or LAMA/LABA, the threshold of $\geqslant 300$ eosinophils. $\mu \mathrm{L}^{-1}$ can be used across all COPD patients who require further treatment to prevent exacerbations to favour the choice of ICS/LABA. A lower threshold $\left(>100\right.$ eosinophils $\left.\mu \mathrm{L}^{-1}\right)$ may be used in patients at high exacerbation risk (two or more moderate exacerbations or one severe exacerbation in the previous year) to support ICS/LABA use, as ICS effects appear to be greater in such high-risk individuals.

The GOLD 2019 report uses the word "consider" when making treatment recommendations concerning blood eosinophils for two reasons: 1) this biomarker provides a degree of probability (not certainty) regarding whether ICS treatment will be beneficial and the magnitude of effect, and 2) other clinical characteristics including the risk of side-effects must also be considered on an individual basis.

For patients already taking LAMA/LABA who are still having exacerbations, we suggest the threshold of $>100$ eosinophils $\mu \mathrm{L}^{-1}$ to identify individuals with a greater likelihood of achieving clinical benefit when escalating to triple therapy. The continuous nature of the relationship between blood eosinophil counts and ICS benefits means that the magnitude of effect on exacerbations will be greater at higher eosinophil counts, particularly $\geqslant 300$ eosinophils $\mu \mathrm{L}^{-1}$. For patients with $<100$ eosinophils $\mu \mathrm{L}^{-1}$, the escalation to triple therapy is unlikely to have a major influence on exacerbations. Other options include the addition of roflumilast or azithromycin [46, 47]. 


\section{MANAGEMENT CYCLE}

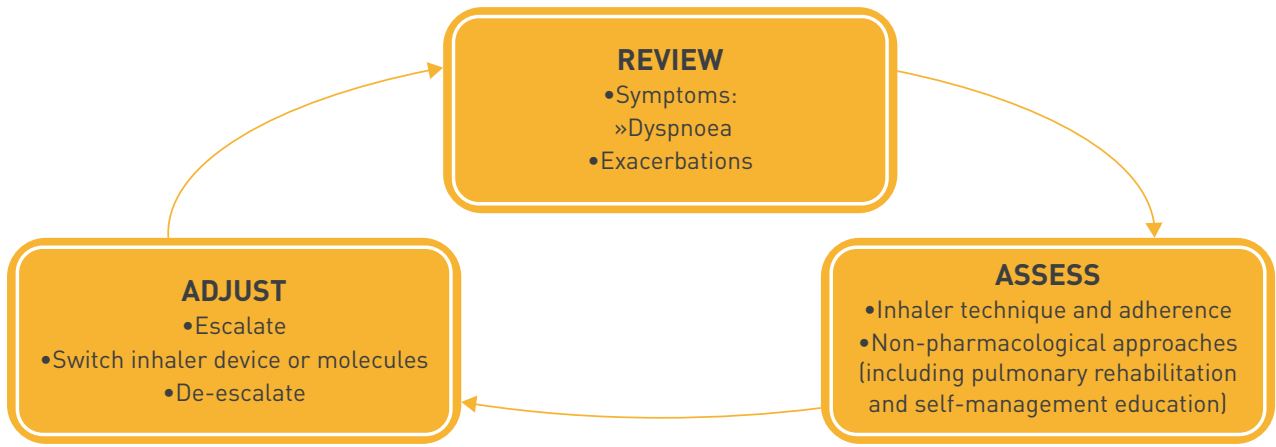

FIGURE 4 Global Initiative for Chronic Obstructive Lung Disease 2019 management cycle recommendations. Reproduced with permission from [17].

Advice is provided regarding the discontinuation of ICS, either by the de-escalation from triple therapy to LAMA/LABA or switching from ICS/LABA to LAMA/LABA. The common clinical scenarios when this may be considered are 1) concerns about side-effects (e.g. likelihood and impact of pneumonia), 2) inappropriate original indication (e.g. the patient had no history of exacerbations and ICS had been prescribed to manage symptoms) and 3) lack of response to ICS. The withdrawal of ICS should be closely monitored, with evidence indicating that the greatest probability of a deleterious effect is in patients with $\geqslant 300$ eosinophils $\mu \mathrm{L}^{-1}$.

An important addition to the pharmacological management section is the management cycle (figure 4), which describes the process of review of symptoms and exacerbations followed by assessment of inhaler technique and adherence as well as non-pharmacological approaches including pulmonary rehabilitation and self-management education. Assessing, treating and following comorbidities also need to be considered throughout the management cycle. This provides a wider holistic view of the many factors to be evaluated before deciding whether to adjust pharmacological treatment.

\section{Conclusions}

The changes to GOLD 2019 reflect an evolution based on recent evidence, rather than change of direction, towards a more personalised approach to COPD management advocated in previous GOLD reports. The focus on managing symptoms and reducing exacerbation risk remains the same. Blood eosinophils have been added in order to help clinicians better manage decisions regarding the benefits versus risks of using ICS. Blood eosinophils provide information regarding probability of benefit and the interpretation of this information is clearer in patients with high exacerbation risk. Clinical decisions regarding the use of ICS-containing combination treatments must focus on exacerbation risk, supported by eosinophil biomarker information, and evaluate side-effect risk for each individual.

GOLD 2019 pharmacological treatment recommendations often provide more than one choice, as evidence has shown these to be effective options. This creates complexity in decision making, in contrast to the simplicity of recommending only one treatment option in each situation. However, the heterogeneity of COPD patients means that treatment recommendations and algorithms should allow flexibility for the individual clinical characteristics and needs of each patient to be taken into account, as well as differences between healthcare systems. GOLD 2019 attempts to provide flexibility in this context, allowing different treatment choices and also providing a framework to help clinicians choose. The area of most debate and complexity is the use of combination inhalers to prevent exacerbations. Recent clinical evidence shows that each of these combination inhalers can be regarded as optimum treatments in some patients, who can be identified using clinical characteristics and a blood biomarker [9, 10]. Individualisation of COPD pharmacological treatment has progressed significantly since the days of FEV1-guided pharmacological management [48].

Acknowledgements: D. Singh and J. Vestbo are supported by the NIHR Manchester Biomedical Research Centre. This report from the GOLD science committee is not the GOLD Executive Summary.

Conflict of interest: D. Singh reports grants and personal fees from GlaxoSmithKline, AstraZeneca, Boehringer Ingelheim, Chiesi, Glenmark, Menarini, Mundipharma, Novartis, Pfizer, Pulmatrix, Therevance and Verona, personal fees from Cipla, Genentech and Peptinnovate, outside the submitted work. A. Agusti reports personal fees from AstraZeneca, Chiesi and Nuvaira, grants and personal fees from Menarini and GlaxoSmithKline, outside the submitted 
work. A. Anzueto reports grants and personal fees for consultancy from GlaxoSmithKline, personal fees for consultancy from AstraZeneca, Novartis, Boehringer Ingelheim and Sunovion Pharmaceutical, outside the submitted work. P.J. Barnes reports grants and personal fees from AstraZeneca and Boehringer Ingelheim, personal fees from Pieris, Novartis and Teva, outside the submitted work. J. Bourbeau reports grants from CIHR, Canadian Respiratory Research Network (CRRN), Foundation of the MUHC and Aerocrine, personal fees for consultancy and lecturing from the Canadian Thoracic Society and CHEST, grants and personal fees for advisory work and lecturing from AstraZeneca, Boehringer Ingelheim, Grifols, GlaxoSmithKline, Novartis and Trudell, outside the submitted work. B.R. Celli reports grants and research support from AstraZeneca, personal fees for consulting and scientific committee membership from GlaxoSmithKline, personal fees for consulting from Boehringer Ingelheim, Novartis, Sanofi-Aventis and Menarini, outside the submitted work. G.J. Criner reports grants and personal fees from GlaxoSmithKline, Boehringer Ingelheim, Chiesi, Mereo, AstraZeneca, Pulmonx, Pneumrx, Olympus, Broncus, Lungpacer, Nuvaira, ResMed, Respironics and Patara, personal fees from Verona, BTG, EOLO and NGM, grants from Alung, Fisher Paykel and Galapagos, outside the submitted work. P. Frith reports non-financial support to attend a scientific committee meeting from Global Initiative for Chronic Obstructive Lung Disease (GOLD), during the conduct of the study; personal fees for advisory board membership from AstraZeneca, personal fees and non-financial support for advisory board work, chairing independent conference organising committees and lecturing from Boehringer Ingelheim and Novartis, non-financial support for attending educational meetings from GlaxoSmithKline, non-financial support for attending committee and board meetings from Lung Foundation Australia (LFA), personal fees and non-financial support for advisory board work from CSL Behring, outside the submitted work. D.M.G. Halpin reports personal fees and non-financial support from Boehringer Ingelheim and Novartis, personal fees from AstraZeneca, Chiesi, GlaxoSmithKline and Pfizer, outside the submitted work. M. Han reports personal fees from GlaxoSmithKline, Boehringer Ingelheim and AstraZeneca, research support from Novartis and Sunovion, outside the submitted work. M.V. López Varela has nothing to disclose. F. Martinez reports personal fees for organising CME programmes and non-financial support for travel from the American College of Chest Physicians, Continuing Education, Inova Fairfax Health System, MD Magazine, Miller Communications, National Association for Continuing Education, PeerView Communications, Prime Communications, Puerto Rican Respiratory Society, Potomac, University of Alabama Birmingham, Physicians Education Resource and Canadian Respiratory Network, personal fees for advisory board and steering committee work, and lecturing, and non-financial support for travel from AstraZeneca, personal fees for advisory board and data safety and monitoring board work, and lecturing, non-financial support for travel from Boehringer Ingelheim, non-financial support for advisory board work from ProterrixBio, personal fees for organising CME programmes from Columbia University Integritas, Methodist Hospital Brooklyn, New York University, UpToDate, WebMD/MedScape, Western Connecticut Health Network, Academic CME, PlatformIQ, Rockpointe, Rare Disease Healthcare Communications and France Foundation, personal fees for advisory board work and non-financial support for travel from ConCert, Roche, Sunovion, Theravance and Teva, personal fees for advisory board and data safety and monitoring board work and non-financial support for travel from Genentech, personal fees for advisory board, steering committee and data safety and monitoring board work, and lecturing, and non-financial support for travel from GlaxoSmithKline, personal fees for advisory board work and lecturing, and non-financial support for travel from Novartis and Chiesi, personal fees for advisory board and steering committee work, and non-financial support for travel from Pearl Pharmaceuticals, personal fees for teleconference involvement from Unity, non-financial support for steering committee work from Afferent/Merck, Gilead, Veracyte, Prometic, Bayer and ProMedior, non-financial support for teleconferencing and steering committee work from Nitto, personal fees for consultancy and steering committee work from Patara, non-financial support for data safety and monitoring board work and steering committee from Biogen, personal fees for advisory board work and support for meeting attendance from Zambon, personal fees for editorial board work from the American Thoracic Society, grants from NIH (IPF UO1, COPD UO1/RO1), and non-financial support for consultancy from Bridge Biotherapeutics, outside the submitted work. M. Montes de Oca has nothing to disclose. A. Papi reports grants, personal fees for board membership, consultancy, lecturing and travel reimbursement from Chiesi, AstraZeneca, GlaxoSmithKline, Boehringer Ingelheim, Mundipharma and Teva, grants, personal fees for lecturing and travel reimbursement from Menarini, personal fees for lecturing and travel reimbursement from Novartis, Zambon and Sanofi, outside the submitted work. I.D. Pavord reports personal fees for lecturing, advisory board work and travel expenses from AstraZeneca, GlaxoSmithKline, Boehringer Ingelheim and Teva, grants and personal fees for lecturing, advisory board work and travel expenses from Chiesi, personal fees for advisory board work from Sanofi/Regeneron, Merck, Novartis, Knopp and Roche/Genentech, personal fees for lecturing from Circassia and Mundipharma, grants and personal fees for advisory board work from Afferent, outside the submitted work. N. Roche reports grants and personal fees from Boehringer Ingelheim, Novartis and Pfizer, personal fees from Teva, GlaxoSmithKline, AstraZeneca, Chiesi, Mundipharma, Sanofi, Sandoz, 3M and Zambon, outside the submitted work. D.D. Sin reports grants from Merck, personal fees for advisory meetings from Sanofi-Aventis and Regeneron, grants and personal fees for lecturing and advisory board work from Boehringer Ingelheim and AstraZeneca, personal fees for lecturing and advisory board work from Novartis, outside the submitted work. R. Stockley reports personal fees for advisory board membership and lecturing from AstraZeneca, personal fees for advisory board membership from MedImmune, Almirall, Kamada, Baxter, Chiesi and Polyphor, personal fees for lecturing from Nycomed, Takeda and GlaxoSmithKline, personal fees for advisory board membership, lecturing and travel to meetings from Boehringer Ingelheim, grants and personal fees for advisory board membership, lecturing and travel to meetings from CSL Behring, outside the submitted work. J. Vestbo reports personal fees for consultancy and lecturing from GlaxoSmithKline, Chiesi Pharmaceuticals, Boehringer Ingelheim, Novartis and AstraZeneca, grants from Boehringer Ingelheim, outside the submitted work. J.A. Wedzicha reports grants and travel expenses from GlaxoSmithKline, Boehringer Ingelheim, Novartis and AstraZeneca, and grants from Johnson and Johnson, and Chiesi, outside the submitted work. C. Vogelmeier reports personal fees from Almirall, Cipla, Berlin-Chemie/Menarini, CSL Behring and Teva, grants and personal fees from AstraZeneca, Boehringer Ingelheim, Chiesi, GlaxoSmithKline, Grifols, Mundipharma, Novartis and Takeda, grants from German Federal Ministry of Education and Research (BMBF) Competence Network Asthma and COPD (ASCONET), Bayer Schering Pharma AG, MSD and Pfizer, outside the submitted work.

\section{References}

1 Singh D, Roche N, Halpin D, et al. Current controversies in the pharmacological treatment of chronic obstructive pulmonary disease. Am J Respir Crit Care Med 2016; 194: 541-549. 
2 Woodruff PG, Agusti A, Roche N, et al. Current concepts in targeting chronic obstructive pulmonary disease pharmacotherapy: making progress towards personalised management. Lancet 2015; 385: 1789-1798.

3 Agusti A, Fabbri LM, Singh D, et al. Inhaled corticosteroids in COPD: friend or foe? Eur Respir J 2018; 52: 1801219.

4 Kolsum U, Damera G, Pham TH, et al. Pulmonary inflammation in patients with chronic obstructive pulmonary disease with higher blood eosinophil counts. J Allergy Clin Immunol 2017; 140: 1181-1184.

5 Bafadhel M, Pavord ID, Russell REK. Eosinophils in COPD: just another biomarker? Lancet Respir Med 2017; 5 $747-759$.

6 Brightling CE, McKenna S, Hargadon B, et al. Sputum eosinophilia and the short term response to inhaled mometasone in chronic obstructive pulmonary disease. Thorax 2005; 60: 193-198.

7 Brightling CE, Monteiro W, Ward R, et al. Sputum eosinophilia and short-term response to prednisolone in chronic obstructive pulmonary disease: a randomised controlled trial. Lancet 2000; 356: 1480-1485.

8 Calverley PMA, Tetzlaff K, Vogelmeier C, et al. Eosinophilia, frequent exacerbations, and steroid response in chronic obstructive pulmonary disease. Am J Respir Crit Care Med 2017; 196: 1219-1221.

9 Lipson DA, Barnhart F, Brealey N, et al. Once-daily single-inhaler triple versus dual therapy in patients with COPD. N Engl J Med 2018; 378: 1671-1680.

10 Papi A, Vestbo J, Fabbri L, et al. Extrafine inhaled triple therapy versus dual bronchodilator therapy in chronic obstructive pulmonary disease (TRIBUTE): a double-blind, parallel group, randomised controlled trial. Lancet 2018; 391: 1076-1084.

11 Pascoe S, Locantore N, Dransfield M, et al. Blood eosinophil counts, exacerbations, and response to the addition of inhaled fluticasone furoate to vilanterol in patients with chronic obstructive pulmonary disease: a secondary analysis of data from two parallel randomised controlled trials. Lancet Respir Med 2015; 3: 435-442.

12 Siddiqui SH, Guasconi A, Vestbo J, et al. Blood eosinophils: a biomarker of response to extrafine beclomethasone/ formoterol in chronic obstructive pulmonary disease. Am J Respir Crit Care Med 2015; 192: 523-525.

13 Vestbo J, Papi A, Corradi M, et al. Single inhaler extrafine triple therapy versus long-acting muscarinic antagonist therapy for chronic obstructive pulmonary disease (TRINITY): a double-blind, parallel group, randomised controlled trial. Lancet 2017; 389: 1919-1929.

14 Vogelmeier CF, Criner GJ, Martinez FJ, et al. Global Strategy for the Diagnosis, Management, and Prevention of Chronic Obstructive Lung Disease 2017 Report. GOLD Executive Summary. Am J Respir Crit Care Med 2017; 195: $557-582$.

15 Singh D, Barnes PJ, Stockley R, et al. Pharmacological treatment of COPD: the devil is always in the detail. Eur Respir J 2018; 51: 1800263.

16 Calverley PMA, Anzueto AR, Carter K, et al. Tiotropium and olodaterol in the prevention of chronic obstructive pulmonary disease exacerbations (DYNAGITO): a double-blind, randomised, parallel-group, active-controlled trial. Lancet Respir Med 2018; 6: 337-344.

17 Global Initiative for Chronic Obstructive Lung Disease. Global Strategy for the Diagnosis, Management, and Prevention of Chronic Obstructive Pulmonary Disease. 2019. https:/goldcopd.org/wp-content/uploads/2018/11/ GOLD-2019-v1.7-FINAL-14Nov2018-WMS.pdf Date last accessed: March 6, 2019.

18 Faner R, Noell G, Badia JR, et al. Distribution, temporal stability and association with all-cause mortality of the 2017 GOLD groups in the ECLIPSE cohort. Respir Med 2018; 141: 14-19.

19 Agustí A, Bafadhel M, Beasley R, et al. Precision medicine in airway diseases: moving to clinical practice. Eur Respir J 2017; 50: 1701655

20 Rutgers SR, Timens W, Kaufmann HF, et al. Comparison of induced sputum with bronchial wash, bronchoalveolar lavage and bronchial biopsies in COPD. Eur Respir J 2000; 15: 109-115.

21 Singh D, Kolsum U, Brightling CE, et al. Eosinophilic inflammation in COPD: prevalence and clinical characteristics. Eur Respir J 2014; 44: 1697-1700.

22 Kolsum U, Donaldson GC, Singh R, et al. Blood and sputum eosinophils in COPD; relationship with bacterial load. Respir Res 2017; 18: 88.

23 Boorsma M, Lutter R, van de Pol MA, et al. Repeatability of inflammatory parameters in induced sputum of COPD patients. COPD 2007; 4: 321-329.

24 Brightling CE, Monterio W, Green RH, et al. Induced sputum and other outcome measures in chronic obstructive pulmonary disease: safety and repeatability. Respir Med 2001; 95: 999-1002.

25 Eltboli O, Mistry V, Barker B, et al. Relationship between blood and bronchial submucosal eosinophilia and reticular basement membrane thickening in chronic obstructive pulmonary disease. Respirology 2015; 20: 667-670.

26 Landis SH, Suruki R, Hilton E, et al. Stability of blood eosinophil count in patients with COPD in the UK Clinical Practice Research Datalink. COPD 2017; 14: 382-388.

27 Southworth T, Beech G, Foden P, et al. The reproducibility of COPD blood eosinophil counts. Eur Respir J 2018; 52: 1800427.

28 Yun JH, Lamb A, Chase R, et al. Blood eosinophil thresholds and exacerbations in chronic obstructive pulmonary disease. J Allergy Clin Immunol 2018; 141: 2037-2047.

29 Oshagbemi OA, Burden AM, Braeken DCW, et al. Stability of blood eosinophils in patients with chronic obstructive pulmonary disease and in control subjects, and the impact of sex, age, smoking, and baseline counts. Am J Respir Crit Care Med 2017; 195: 1402-1404.

30 Casanova C, Celli BR, de-Torres JP, et al. Prevalence of persistent blood eosinophilia: relation to outcomes in patients with COPD. Eur Respir J 2017; 50: 1701162.

31 Landis S, Suruki R, Maskell J, et al. Demographic and clinical characteristics of COPD patients at different blood eosinophil levels in the UK Clinical Practice Research Datalink. COPD 2018; 15: 177-184.

32 Bafadhel M, Peterson S, De Blas MA, et al. Predictors of exacerbation risk and response to budesonide in patients with chronic obstructive pulmonary disease: a post-hoc analysis of three randomised trials. Lancet Respir Med 2018; 6: 117-126.

33 Pavord ID, Lettis S, Locantore $\mathrm{N}$, et al. Blood eosinophils and inhaled corticosteroid/long-acting beta-2 agonist efficacy in COPD. Thorax 2016; 71: 118-125.

34 Wedzicha JA, Banerii D, Chapman KR, et al. Indacaterol-glycopyrronium versus salmeterol-fluticasone for COPD. N Engl J Med 2016; 374: 2222-2234. 

186: $48-55$.

41 Vedel-Krogh S, Nielsen SF, Lange P, et al. Blood eosinophils and exacerbations in chronic obstructive pulmonary disease. The Copenhagen General Population Study. Am J Respir Crit Care Med 2016; 193: 965-974.

42 Hastie AT, Martinez FJ, Curtis JL, et al. Association of sputum and blood eosinophil concentrations with clinical measures of COPD severity: an analysis of the SPIROMICS cohort. Lancet Respir Med 2017; 5: 956-967.

43 Suissa S, Dell'Aniello S, Ernst P. Comparative effectiveness of LABA-ICS versus LAMA as initial treatment in COPD targeted by blood eosinophils: a population-based cohort study. Lancet Respir Med 2018; 6: 855-862.

44 Singh D, Ferguson GT, Bolitschek J, et al. Tiotropium+olodaterol shows clinically meaningful improvements in quality of life. Respir Med 2015; 109: 1312-1319.

45 Mahler DA, Decramer M, D’Urzo A, et al. Dual bronchodilation with QVA149 reduces patient-reported dyspnoea in COPD: BLAZE study. Eur Respir J 2014; 43: 1599-1609.

46 Martinez FJ, Calverley PM, Goehring UM, et al. Effect of roflumilast on exacerbations in patients with severe chronic obstructive pulmonary disease uncontrolled by combination therapy (REACT): a multicentre randomised controlled trial. Lancet 2015; 385: 857-866.

47 Albert RK, Connett J, Bailey WC, et al. Azithromycin for prevention of exacerbations of COPD. N Engl J Med 2011; 365: 689-698.

48 Rabe KF, Hurd S, Anzueto A, et al. Global strategy for the diagnosis, management, and prevention of chronic obstructive pulmonary disease: GOLD executive summary. Am J Respir Crit Care Med 2007; 176: 532-555. 